\title{
Effect of e-Commerce Platforms towards Increasing Merchant's Income in Malaysia
}

\author{
M.Hafiz Yusoff ${ }^{*}, 1$, Mohammad Ahmed Alomari ${ }^{2}$, Nurul Adilah Abdul Latiff ${ }^{3}$, Motea S. Alomari ${ }^{4}$ \\ Faculty of Informatics and Computing, Universiti Sultan Zainal Abidin (UniSZA) ${ }^{1,2}$ \\ Faculty of Ocean Engineering Technology \& Informatics, Universiti Malaysia Terengganu (UMT) ${ }^{3}$ \\ Faculty of Engineering, Universiti Putra Malaysia, Selangor, Malaysia ${ }^{4}$
}

\begin{abstract}
In 2018, 'Hootsuite' and 'We Are Social' have reported in their Digital Report that Malaysian Internet users had increased to $\mathbf{2 5 . 0 8}$ million users, representing $79 \%$ of Malaysian population. However, some reports indicate that even with the enhancement of digital technology, many merchants are still not using any e-commerce platform and being sceptic about it. With the pervasive increase of the Internet users, many other reports had been published to understand the relationship between e-commerce and the increasing of merchants' income. Therefore, the objective of this research is to study the involvement of Malaysian merchants in e-commerce platforms. A sample of 1060 respondents had been selected randomly across Malaysia to participate in this research by answering a set of survey questions given online. In general, the results show that many merchants have realized the existence of e-commerce and they are familiar with it. However, they have only been utilizing it for purchasing goods and services. On the other hand, a few numbers of Malaysian merchants do engage with some type of ecommerce platforms to operate their businesses. In addition, the research is performed to identify the impact of using e-commerce on Malaysian merchants' income.
\end{abstract}

Keywords-Income increase; e-commerce; merchant; Malaysia; e-retailing

\section{INTRODUCTION}

The boom of Internet era accompanied with the Industrial Revolution 4.0 (IR 4.0) rising in the horizon, all that had enabled e-commerce and m-commerce (mobile commerce) to play a vital role in transforming how electronic trading of selling and buying have evolved tremendously [1]. 5G cellular services as well as other similar technologies are expected to have revolutionary effect on e-commerce activities. That will attract users to engage more in e-commerce services and make more buy and selling online. For selling consumers, that will open new perspectives for larger businesses and higher income [2]. It is estimated that e-commerce jobs introduced by companies have been risen by 400,000 within the last ten years, when compared to 140,000 decline in traditional trading; with center jobs pay $31 \%$ more than traditional retail jobs in the same area [3].

E-commerce is a process of buying and selling goods and services. It also contains all intermediate process including advertising, promoting, negotiating, ordering, delivering, and also after sales services. E-commerce also includes managing transaction of any digital goods such as Electronic Fund Transfer (EFT) as well as selling and purchasing of electronic news and information of stock prices including classified advertisement [4]. Nowadays, every second means a new product is being introduced and promoted over the Internet when compared to physical premises like stores and shops which has slower trading. The vast technology advancement as well as 4G-5G services has enabled Internet to become a medium for selling and purchasing various types of products, new and old, via e-commerce platforms. Such type of trading offers more speed and ease for the whole process compared to traditional business method. One doesn't have to be present physically or face to face to complete a purchase or deal. Ecommerce also has been proven as the best method to operate businesses in this era of globalization where businesses are boundless for everyone [5,6].

According to a research conducted [7, 8], there are differences on how the men and women uses the Internet. Men uses the Internet less for selling stuff while women showed more entrepreneurial spirit by selling their goods as well as offering services via multiple e-commerce platforms. The reason might be that most women involved as active merchants in e-commerce are housewives trying to make some pocket money for themselves or their families. Most merchants agree that by using e-commerce platforms, they can reach even further in terms of customers' acquisition and distance.

Sales target is always the first thing in doing businesses where a positive cashflow is essential to keep a business running. Thus, by using e-commerce, lesser cost in promoting and advertising can be induced to reach more potential customers when compared to slower sales in traditional method [3]. However, there are various risks in doing transaction over the Internet. First, the risk of encountering a scammer is far more frequent due to the ease of creating fake account. Second risk might be the low security options offered by e-commerce platforms. In order to perform online transaction, one must provide some basic information such as e-mail address and payment account information such as debit or credit card. Although the data privacy policy has been enforced by lawmakers, it is still exposed to hacking threats. These information can relatively easily be accessed by hackers hunting for valuable data over the Internet and then sell them to third party for any unhealthy purpose [9-12].

Malaysia is considered one of the promising countries to get involved deeper in e-commerce activities in future. During recent years in Malaysia, the technology literacy has increased

\footnotetext{
*Corresponding Authors
} 
rapidly following the big changes in government policy, especially in education where the ministry had spent a lot of budget to adopt digital technology into classrooms. The Ministry of Communication and Multimedia has also enforced low cost for Internet and has encouraged many Malaysian to dive into the digital world. These policies have tremendously affected Malaysian lifestyle especially on how they shop and purchase goods and services [13-15]. Internet has become the largest medium of money transaction globally.

In recent years, Malaysians have been exposed to many entrepreneurship programs which significantly increased their interest to engage in building their own start-up companies. However, this progress has risen a question; how far these emerging business owners are involved with e-commerce. This research is conducted focusing on two main objectives:

1) To identify the involvement in using e-commerce platforms among Malaysian merchants.

2) To study the impact of using e-commerce platforms towards merchants' income.

The rest of this paper is organized as follows. Details of current research related to this work will be discussed in Section 2. In Section 3, methodology aspects and tools used as well as sampling details will be elaborated. In Sections 4 and 5 , the results came out of this study as well as discussion of that results will be presented respectively. Finally, the conclusion of the study will be discussed in Section 6 .

\section{LITERATURE REVIEW}

The rapid growth of e-commerce and $\mathrm{m}$-commerce all over the globe is undeniable. Since the year 2000, the growing adoption of Internet which increased from $52 \%$ of total population to $89 \%$ in 2018 , has boosted e-commerce trading and sales tremendously [16]. According to Ecommerce Foundation 2018 report, out of the 32 million population of Malaysia, the e-commerce shoppers exceeded $70 \%$ with high Internet penetration of $82 \%$ in this country. In addition, $40 \%$ of e-shoppers who purchased online they did that via phone in 2017(Q3). Fig. 1 depicts some details of that e-commerce growth. That is understood with continuous efforts of Malaysian government to facilitate and push e-commerce usage further. In year 2016, the Malaysian Ministry of International Trade and Industry (Miti) has launched a new ecommerce initiative aiming to bring $80 \%$ of small and medium-sized companies into the e-commerce world [14].

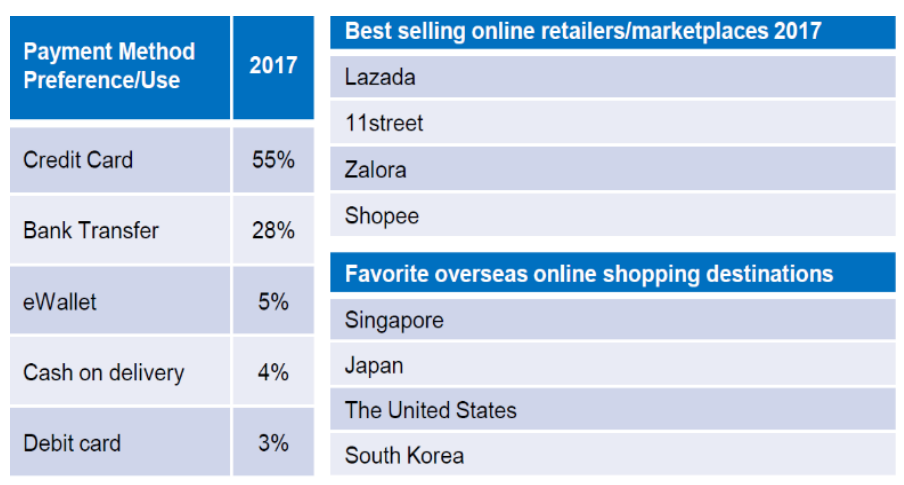

Fig. 1. Malaysia E-Commerce Facts and Figures.
The immense growth of electronic commerce in Malaysia has pushed research community to study that phenomenon as well as problems and challenges facing it. Authors in [17] investigated the effect of online trading on daily life of Malaysians, the development, current status and future trends of online shopping in Malaysia as well as factors that influence e-commerce. They also studied initiatives to raise online shopping by various parties. Ramlan et al. [18] studied the dominant factors that influence Malaysian shoppers to buy online. Usefulness, saving time, and ease of use were the main factors to affect consumers to participate in e-commerce. On the other hand however, privacy, trust, and safety were the main concerns and challenges for e-shoppers. Authors in [4] tried to provide an assessment, evaluation, and understanding of the different aspects on e-commerce in Malaysia. They implemented various tests to compare online consumers versus the offline consumers. Marzuki et al. [15] have used a sample of 160 university students to study how deep they get involved in e-commerce as well as factors behind that. It shows that student involvement is high in e-buying, however it becomes low when it comes to e-business and trading.

E-commerce industry is faced with various challenges. That may include fear of cyber security threats, lack of understanding, limited skills of digital marketing, lack of knowledge regarding market access and regulations in and out of country, and finally lack of experience personnel to run ecommerce activities. Hanefah et al. [19] investigated the tax problems posed by e-commerce and solutions for that problem. Their findings show that tax administration was the main reasons to affect e-commerce growth, followed by double taxation, tax evasion, and tax avoidance. Their results show that subjects perceive e-commerce as creating tax problems.

\section{RESEARCH METHODOLOGY}

Various types of research may different type of methods and tools to achieve its target objectives. In this research, a structured questionnaire with descriptive survey has been used to identify the involvement of Malaysians in e-commerce and how e-commerce is affecting merchant's income. The survey was used as a primary data to answer research questions. So, this research is a survey-based research which is intended to identify the impact of e-commerce towards increasing the income of Malaysian merchants. Tuckman [20] stated that survey studies are an efficient way to get information from respondent. It is generally effective way to use descriptive techniques to measure and evaluate the achievement, behavior, perception, and involvement in a specific subject [21].

For this research, a series of 8 questions is distributed via Google Forms. The sample population is a potential Malaysian user of any e-commerce platform. A total of 1300 respondents have completed the questionnaire survey where the responses were screened for errors or incomplete details. Upon the completion of screening process, only 1060 survey forms were considered valid and ready to be entered to data analysis stage. This provides us with a success rate of about $82 \%$ which is considered to be appropriate in view of cost and time limitations. The confidence level as well as margin of 
error used was $95 \%$ and $3 \%$ respectively. SPSS statistical software version 23 on Windows 10, was used to data and findings in this study. Various statistical techniques were used to analyze data in this study. Frequency Distribution Analysis technique were used to determine the demographic details of the survey respondents. Cross tabulation and the Pearson ChiSquare Test were also used to analyze various relationships in data under study [22]. The group of respondents has been categorized based on sex, age, and occupation. Furthermore, the selected sample consists of respondents from four different jobs within Malaysia, namely students, private workers, government employees, and merchants or self-employed.

\section{RESEARCH FINDINGS}

In this section, the results obtained from this study will be depicted where the data analysis collected will be presented and discussed.

\section{A. Respondent Profile}

Table I shows the entire profile of 1060 respondents involved in the survey. They are categorized based on sex, age, and occupation where they are all Malaysians. Table shows that $66 \%$ of respondents are women and $34 \%$ are men. In this study, most respondents lie within 20-29 years old with about $61 \%$ where students are dominating the survey sample by $64 \%$ of total respondents.

\section{B. Awareness of e-Commerce}

Table II depicts the distribution of respondents towards how they are aware of e-commerce. The data conclude that majority of Malaysians are already aware of the existence of e-commerce platforms with more than $82 \%$ answered 'yes' while only $18 \%$ said that they have never heard about ecommerce.

\section{Respondent Status}

Table III identify either the respondent is a merchant or not. Surprisingly, despite being well literate in e-commerce, only 22 respondents $(21 \%)$ involve as active merchants in any e-commerce platforms, while the balance of 84 respondents $(79 \%)$ are not online merchant.

TABLE. I. RESPONDENT PROFILE

\begin{tabular}{|l|l|l|l|}
\hline Item & & Frequency & Percentage \\
\hline \multirow{4}{*}{ Sex } & Men & 362 & $34.2 \%$ \\
\cline { 2 - 4 } & Women & 698 & $65.8 \%$ \\
\hline \multirow{5}{*}{ Age } & 19 and below & 91 & $8.6 \%$ \\
\cline { 2 - 4 } & $20-29$ year old & 642 & $60.6 \%$ \\
\cline { 2 - 4 } & $30-39$ year old & 154 & $14.5 \%$ \\
\cline { 2 - 4 } & $40-49$ year old & 102 & $9.6 \%$ \\
\cline { 2 - 4 } & $50-59$ year old & 71 & $6.7 \%$ \\
\cline { 2 - 4 } & 60 and above & 0 & $0 \%$ \\
\hline \multirow{5}{*}{ Occupation } & Student & 677 & $63.9 \%$ \\
\cline { 2 - 4 } & Merchant/Self-Employed & 102 & $9.6 \%$ \\
\cline { 2 - 4 } & Government staff & 207 & $19.5 \%$ \\
\cline { 2 - 4 } & Private sector worker & 74 & $7 \%$ \\
\hline
\end{tabular}

TABLE. II. KNOWLEDGE OF E-COMMERCE

\begin{tabular}{|l|l|l|}
\hline \multicolumn{3}{|l|}{ Do you know anything about e-comerce? } \\
\hline & Amount & Percentage \\
\hline Yes & 869 & $81 \%$ \\
\hline No & 191 & $18 \%$ \\
\hline
\end{tabular}

TABLE. III. RESPONDENT STATUS

\begin{tabular}{|l|l|l|}
\hline \multicolumn{2}{|l|}{ Do you practice online business? } \\
\hline & Amount & Percentage \\
\hline Yes & 224 & $21.1 \%$ \\
\hline No & 836 & $78.9 \%$ \\
\hline
\end{tabular}

\section{Platforms used to Promote Goods and Services}

Based on Table IV, social media is identified as the most frequently used platforms to promote goods and services. This must be due to many Malaysian spent hours using social media. $63 \%$ of respondents use social media as the data shows. Large online markets such as Lazada and Shoppe are also being favored by respondents as much as $19 \%$ of total respondents. Falling behind are other platforms; mobile applications $8.6 \%$, self-published websites $8 \%$ and others by less than $2 \%$.

\section{E. Impact of using e-Ccommerce Platforms Towards Increasing Income}

Based on Table $\mathrm{V}$, findings show that 1035 respondents (98\%) agree that e-commerce platforms can provide positive impact to increase merchants' income. Only $2 \%$ of respondents disagree of the positive impact. The reason is unknown, and this category might need to be surveyed further to study their negative response.

\section{F. Impact of using e-Commerce Platforms Towards Increasing Customers}

This research concurs that majority of respondents (95\%) agree that e-commerce platforms can enable a merchant to reach more customers; and therefore, increasing the amount of sales and profit. Only 5\% of the survey responded by disagreeing as Table VI shows. We were unable to state the reason behind their negative response.

TABLE. IV. PlatForms USED TO PROMOTE GOODS AND SERVICES

\begin{tabular}{|l|l|l|}
\hline Platform & Frequency & Percentage \\
\hline Social media & 667 & $62.9 \%$ \\
\hline Self-published website & 85 & $8 \%$ \\
\hline E-commerce market & 197 & $18.6 \%$ \\
\hline Mobile Applications & 91 & $8.6 \%$ \\
\hline Other & 20 & $1.9 \%$ \\
\hline
\end{tabular}

TABLE. V. IMPACT OF USING E-COMMERCE PLATFORMS TOWARDS INCREASING INCOME

\begin{tabular}{|l|l|l|}
\hline \multicolumn{2}{|c|}{ Do you agree that e-commerce can increase the merchants' income? } \\
\hline & Amount & Percentage \\
\hline Yes & 1035 & $97.6 \%$ \\
\hline No & 25 & $2.4 \%$ \\
\hline
\end{tabular}


TABLE. VI. IMPACT OF USING E-COMMERCE PLATFORMS TOWARDS INCREASING CUSTOMERS

D you agree that e-commerce platforms towards increasing customers?

\begin{tabular}{|l|l|l|}
\hline & Amount & Percentage \\
\hline Yes & 1006 & $94.9 \%$ \\
\hline No & 54 & $5.1 \%$ \\
\hline
\end{tabular}

G. Impact of using e-Commerce Platforms Towards Achieving Higher Sales Target

Table VII shows that more than $90 \%$ of respondents agree that e-commerce platforms can significantly help to increase sales target as it enables higher customer reach. However, 9\% of respondents disagree of the capability of e-commerce platforms to increase sales target.

TABLE. VII. IMPACT OF USING E-COMMERCE PLATFORMS TOWARDS ACHIEVING HIGHER SALES TARGET

Do you agree that e-commerce is able to increase sales target?

\begin{tabular}{|l|l|l|}
\hline & Amount & Percentage \\
\hline Yes & 962 & $90.8 \%$ \\
\hline No & 98 & $9.2 \%$ \\
\hline
\end{tabular}

\section{H. Suggestion to Promote using e-Commerce}

Finally, the research intended to know if the respondents would suggest any e-commerce platforms to the people around them. Results in Table VIII shows that $83 \%$ of them will suggest it to their friends and family while $17 \%$ are not interested to do that.

TABLE. VIII. Suggestion to Promote using e-Commerce

\begin{tabular}{|l|l|l|}
\hline \multicolumn{2}{|l|}{ Would you suggest any e-commerce platforms to your friends and family? } \\
\hline & Amount & Percentage \\
\hline Yes & 884 & $83.4 \%$ \\
\hline No & 176 & $16.6 \%$ \\
\hline
\end{tabular}

\section{DISCUSSION}

In recent years, e-commerce and m-commerce have influenced many Malaysians to participate either as consumers or retailers. Based on this research finding, it shows that Malaysian women are more responsive to the survey conducted than men. The big range of age $(19-60$ years old) proves that senior citizens are also actively engaged with digital transformation of businesses. This is a good sign that Malaysians regardless of age and generations have accepted and adopted the digital technology in their daily life. Findings also show that Malaysians are aware of the existence of ecommerce platforms. Many reports state that Malaysians are one of most active buyers in South East Asia region, but not as a merchant or trader. This research verifies that statement by identifying that $20 \%$ out of the 1060 respondents are not doing any form of businesses online. This research also shows that most respondents use social media $(62 \%)$ as their main platform to promote products online. This indicates that many Malaysians still don't know how to use proper e-commerce platforms to create their own online shops.
By using e-commerce platforms, respondents agree that ecommerce is significantly helping to increase merchants' income. However, the findings found some contradiction since there is small incline on positive impact to increasing customers and sales target. This might be due to bad experience using e-commerce platforms or using unsuitable platforms for their goods and services. Practicing business require a set of skill while using e-commerce platforms to gain more reachability and increase. It is not easy to transform from traditional business method in order to adopt ecommerce platforms. The strategy is totally different between the two methods. Due to the depth of understanding, some merchants did profit from e-commerce platform while some did not. Most probably that might be due to the nature of some businesses which require face to face interaction or to be physically present to make it happen. There are many pros and cons in using e-commerce. It is proven that e-commerce is prone to have some security issues. Additionally, the tendency to encounter scammers are higher in e-commerce than practicing traditional businesses. Nonetheless, data shows that most Malaysians are willing to suggest using e-commerce to their friends and family.

\section{CONCLUSION}

Although E-commerce is considered new to Malaysia, it is picking up fast as the Malaysian government enforces new policies and adapting to Industrial Revolution 4.0. The rising of lots of start-ups also contributes to the emerging of ecommerce platforms used in Malaysia which make more Malaysians to become entrepreneurs every day. However, the usage of proper e-commerce platforms among Malaysian merchants are way too low compared to the number of consumers. In order to encourage the digital transformation of merchants, more initiatives need be done such as developing safer and more secure e-commerce platforms. More education programs on e-commerce should also be available in order to attract more merchants to transform and digitize their businesses. A couple of conclusions can be made based on this research. First, e-commerce is able to increase customer acquisition, sales target and income. Second, Malaysians are active users of e-commerce despite the various threats encountered during the digital business. Furthermore, many more research need be conducted to identify factors that affect e-commerce suitability for Malaysian merchants during new services supported by IR 4.0 and 5G cellular technology.

\section{REFERENCES}

[1] Chao, Chiang-nan. "Emergence Impacts of Mobile Commerce: An Exploratory Study." Journal of Management and Strategy 8.2 (2017): 63-70.

[2] N. Kshetri, "5G in E-commerce activities," IT Prof, vol. 20, no. 4, pp. 73-77, 2019.

[3] M. Mandel, "How Ecommerce Creates Jobs and Reduces Income Inequality," Progressive Policy Institute, 2017.

[4] A. C. P. Harn and A. K. d. H. b. Ismail, "ECommerce: A Study on Online Shopping in Malaysia," Journal of Social Sciences 13.3 pp. 231242, 2006.

[5] R. Tiwari, S. Buse, and C. Herstatt, "From electronic to mobile commerce: technology convergence enables innovative business services," Hamburg University of Technology (TUHH), 2006. 
[6] Garín-Muñoz, Teresa, et al. "Models for individual adoption of eCommerce, eBanking and eGovernment in Spain." Telecommunications Policy 43.1 (2019): 100-111.

[7] S. Rodgers and M. A. Harris, "Gender and e-commerce: An exploratory study," Journal of advertising research, vol. 43, no. 3, pp. 322-329, 2003.

[8] C. V. Slyke, F. Belanger, and R. Hightower, "Understanding genderbased differences in consumer e-commerce adoption," in Proceedings of the 2005 Southern Association of Information Systems Conference, 2005.

[9] A. S. H. M. Rawi, S. Z. Omar, and M. S. S. Ali, "Level of relationship between various selected factors with the intention to use e-commerce among Internet users," Malaysian Journal of Media Studies, vol. 13, no. 2, pp. 11-28, 2011.

[10] Lee, M. Factors influencing the adoption of internet banking: An integration of TAM \& TPB with perceived risk \& perceived benefit. Electronic Commerce Research \& Applications, 8(3), 130-141, 2009.

[11] Ghosh, Anup K., and Tara M. Swaminatha. "Software security and privacy risks in mobile e-commerce." Communications of the ACM 44.2 (2001): 51-57.

[12] Singh, Sachchidanand, and Nirmala Singh. "Internet of Things (IoT): Security challenges, business opportunities \& reference architecture for E-commerce." 2015 International Conference on Green Computing and Internet of Things (ICGCIoT). IEEE, 2015.

[13] Hootsuite, "Digital in 2018 Report", Available from: https://hootsuite.com/pages/digital-in-2018, [Accessed 15 February 2019].
[14] Ecommerce Foundation, "2018 Global Ecommerce Report", https://www.internetalliance.my/wp-content/uploads/ 2018/10/GlobalB2C-e-Commerce-Country-Report-2018.pdf, [Accessed 26 May 2019].

[15] N. Mat, N. Marzuki, J. Alias, and N. A. Abdullah, "Student Involvement in E-Commerce: A Case Study in UKM," Malaysian Journal of Student Advancement, vol. 19, no. 2, pp. 59-69, 2016.

[16] NationMaster, Online Shopping Trends 2019 \& Key Figures - What you need to know, https://www.nationmaster.com/ ecommerce.

[17] Paynter, John, and Jackie Lim. "Drivers and impediments to ecommerce in Malaysia." Malaysian Journal of Library \& Information Science 6.2 (2001): 1-19.

[18] R. Ramlan and F. Z. Omar, "A study on factor that influence online shopping in Malaysia," in 5th International Conference of the Asian Academy of Applied Business (AAAB), 9th - 10th June 2011, Cambodia, 2011.

[19] Hanefah, Hajah Mustafa Mohd, Haslinda Hassan, and Zaleha Othman. "E-commerce Implications Potential Problems and Challenges in Malaysia." International Business Research 1.1 (2008): 43-57.

[20] B. W. Tuckman, Conducting Educational Research. Fort Worth: Harcourt Brace College Publishers, 1990.

[21] W. Wiersma, Research Methods in Education: An Introduction. Boston Allyn and Bacon, 1995.

[22] White, D., and A. Korotayev. "Statistical analysis of cross-tabs." Anthrosciences. org (2004). 